\title{
Computer aided analysis of total knee replacement in rheumatoid arthritis
}

\author{
G. P. ARDEN \\ From the Windsor Group of Hospitals
}

SUMmARY A computer-aided analysis has been carried out on 176 knee replacements performed on 129 patients during the last 12 years. Owing to the variety of knee replacements used, the number of complications seen, and the large quantity of survey data a computer was very helpful in storing this amount of data with facilities for rapid recall of information. The results of the early Shiers knee hinged arthroplasties have been less than $50 \%$ good results, and these were followed by many complications. A smaller number of other knee replacements have been analysed, namely, Freeman-Swanson, Gunston, Sheehan, and Attenborough. The best results were obtained using 60 Attenborough knee prostheses, with a low infection rate of $3 \cdot 3 \%$, a loosening rate of $5 \%$, and good prospects of salvage by fusion of the knee if required.

We have analysed with the aid of a computer the records of 140 patients who have had 200 knee replacements, but complete details of follow-up were available only for 129 patients with 176 knee arthroplasties.

The list of orthopaedic conditions is so large and the complications so numerous that any code is necessarily long and liable to error. The use of computer facilities is essential when handling large quantities of survey data.

Our survey extends back for 12 years and the computer has given us the ability to store a large amount of data over a long period and yet provide rapid recall information (Table 1).

The data extraction sheets which we designed involved asking each patient 170 questions. Our study was necessarily retrospective and the data available were nonstandard, incomplete, and sometimes difficult to interpret.

There has been some variation in the interpretation of the questions, while data skipping has been

Table 1 Computer analysis

1. Retrospective

2. A lot of data can be stored

3. Rapid recall

Accepted for publication 21 May 1982

Correspondence to Mr G. P. Arden, FRCS, 1 Dorset Road, Windsor SL4 3BA. necessary at times owing to inadequate notes (Table 2).

This computational approach not only offers the opportunity of monitoring the performance of different knee prostheses but it enabled us to obtain combined multiple factors which may influence the final result.

\section{Patients and methods}

We have reviewed the complications resulting from 176 knee arthroplasties followed up for a period of 12 years. Almost $90 \%$ of the patients were female, and over a third of the patients required a bilateral arthroplasty. There was a wide age range, from 14-86 years with an average of 51 years (Table 3 ).

Table 2 Problems in computer analysis

1. Misinterpretation

2. Data skipping

3. Time consuming

Table 3 Total knee replacement in rheumatoid arthritis

\begin{tabular}{lrlr}
\hline Clinical material & & & \\
\hline Patients & 129 & Female & 115 \\
Knees & 176 & Male & 14 \\
Bilateral & 47 & & \\
\hline
\end{tabular}

Average age $50 \mathrm{yr}(14-86 \mathrm{yr})$. 
Most of the patients were suffering from rheumatoid arthritis and the younger patients of the 14-25 age group from Still's disease (Table 4).

\section{Results}

We have assessed our results on the range of movement and degree of pain and with a minimum follow-up of 3 years, less than half have a good result (Table 5).

The quick data retrieval procedure available has enabled us to obtain details of the complications and results for each type of knee prosthesis used (Table $6)$.

\section{SHIERS KNEE HINGE ARTHROPLASTY ${ }^{1}$}

\section{(1967-74)}

Our early experience has been with the hinged knee prosthesis (Fig. 1), but we have now abandoned its use owing to the complications which I shall now describe.

We have carried out 80 hinged arthroplasties during the last 12 years. Seven of these patients have died, leaving 63 knees available for follow-up.

Early complications (Table 7). Skin necrosis has occurred in $18 \%$ of patients (Fig. 2). Most were small

Table 4 Diagnosis

\begin{tabular}{lr}
\hline Rheumatoid arthritis & 150 \\
Juvenile chronic arthritis & 24 \\
Psoriatic arthritis & 2 \\
Total & 176 \\
\hline
\end{tabular}

Table 5 Knee arthroplasties

\begin{tabular}{ll}
\hline & \multicolumn{2}{c}{168 Knees } \\
\hline Excellent & 15 \\
Good & $64\} \quad 47 \%$ \\
Fair & 32 \\
Poor & $57\} \quad 53 \%$ \\
\hline
\end{tabular}

Follow-up 3-12 yr. Died, 8.

Table 6 Type of prosthesis

\begin{tabular}{lr}
\hline Hinged & 80 \\
Shiers & \\
Gliding & 19 \\
Freeman-Swanson & 9 \\
Gunston & \\
Linked & 60 \\
Attenborough & 8 \\
Sheehan & 176 \\
Total & \\
\hline
\end{tabular}

Follow-up 3-12 yr.

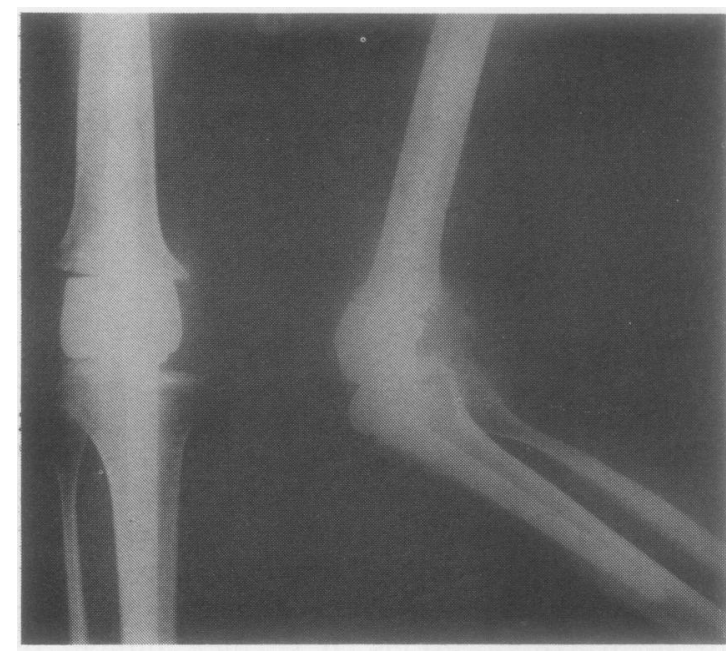

Fig. 1 This patient aged 27 suffering from Still's disease had a Shiers arthroplasty for a stiff and painful right knee. After the operation he developed a sinus which failed to heal, and one year later the prosthesis was removed and the knee successfully fused.

Table 7 Early complications (Shiers)

\begin{tabular}{lr}
\hline Skin necrosis & 13 \\
Haematoma & 12 \\
Infection & 9 \\
Drop foot & 2 \\
Crack in tibia & 2 \\
Penetration of tibial shaft & 2 \\
Ischaemia of foot & 2 \\
Total (57\%) & 42 \\
\hline
\end{tabular}

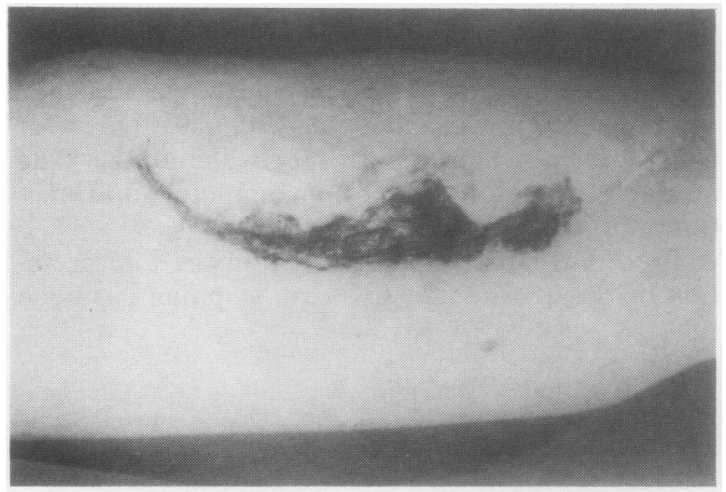

Fig. 2 This patient aged 48 with rheumatoid arthritis had a Shiers arthroplasty on the right knee. Some skin necrosis occurred which took 3 months to heal, and 5 years later she developed a deep infection which required removal of the prosthesis. 
areas that delayed mobilisation, but 2 large areas resulted in a deep infection. Infection occurred mainly in those patients who had been on corticosteroid. Five healed, but 8 persisted, the prosthesis and cement being removed in 5, while 3 had an above-knee amputation.

The 2 patients who developed a drop foot and a 'white foot' had a marked flexion deformity which was corrected too rapidly, and slight flexion of the knee resulted in recovery.

The crack in the tibia was held by the cement and caused no problems, while the penetration of the tibial shaft caused no immediate problems, but one developed a sinus over the tip of the prosthesis 3 years later.

Late complications (Table 8). Fourteen prostheses became loose (19\%), 3 following a fall. Eight of these were revised satisfactorily, but the others required removal of the prosthesis. A late infection developed 1-4 years later in 8 cases. Two of these healed; the rest have had to have the prosthesis and cement removed and an attempt made to fuse the knee.

Four patients had an attrition rupture of the quadriceps tendon over the metal hinge. All were repaired, but only 2 were successful.

The bolt of the prosthesis came out on 2 occasions and was replaced by a further operation.

Results. We have assessed our results, based on the range of movement and degree of pain, after a minimum follow-up of 5 years. On this basis less than half had a good or excellent result, and as the followup lenghthens more complications are appearing (Table 9).

Table 8 Late complications (Shiers)

\begin{tabular}{lr}
\hline Loosening of the prosthesis & 14 \\
Late infection & 8 \\
Extensor lag & 7 \\
Quadriceps rupture & 4 \\
Amputation & 3 \\
Extrusion of bolt & 2 \\
Instability & 2 \\
Skin necrosis & 1 \\
Total $(56 \%)$ & 41 \\
\hline
\end{tabular}

Table 9 Knee hinge arthroplasty (Shiers)

$\left.\begin{array}{lr}\hline \text { Results } & 73 \text { Knees } \\ \hline \text { Excellent } & 5 \\ \text { Good } & 28 \\ \text { Fair } & 7 \\ \text { Poor } & 33\end{array}\right\} 55 \%$

Follow-up 5-12 yr. Died 7.
Conclusions. This type of arthroplasty resulted in (1) relief of pain in the majority; (2) excellent stability; (3) good correction of any deformity; (4) no mechanical failures; (5) $23 \%$ deep infection; (6) $19 \%$ loosening; (7) a salvage procedure, that is fusion, was largely unsucessful.

\section{FREEMAN-SWANSON KNEE PROSTHESIS ${ }^{2}$}

(1972-4)

During the last 7 years we have carried out 19 Freeman-Swanson knee arthroplasties (Fig. 3). The great majority were female and 4 required a bilateral arthroplasty. All the patients were suffering from rheumatoid arthritis or juvenile chronic arthritis.

Complications. Three infections have occurred. These persisted, and the prostheses were removed and a compression arthrodesis carried out. One knee successfully fused but the other 2 failed and have developed a pseudoarthrosis. In 5 patients the tibial prosthesis became loose in 3 cases and the femoral prosthesis in 2 others; all were removed and replaced with an Attenborough prosthesis.

We have had only one case of skin necrosis with this arthroplasty, as there is less dissection required and the patella is not removed. Preservation of the patella gives the knee a more normal appearance (Table 10).

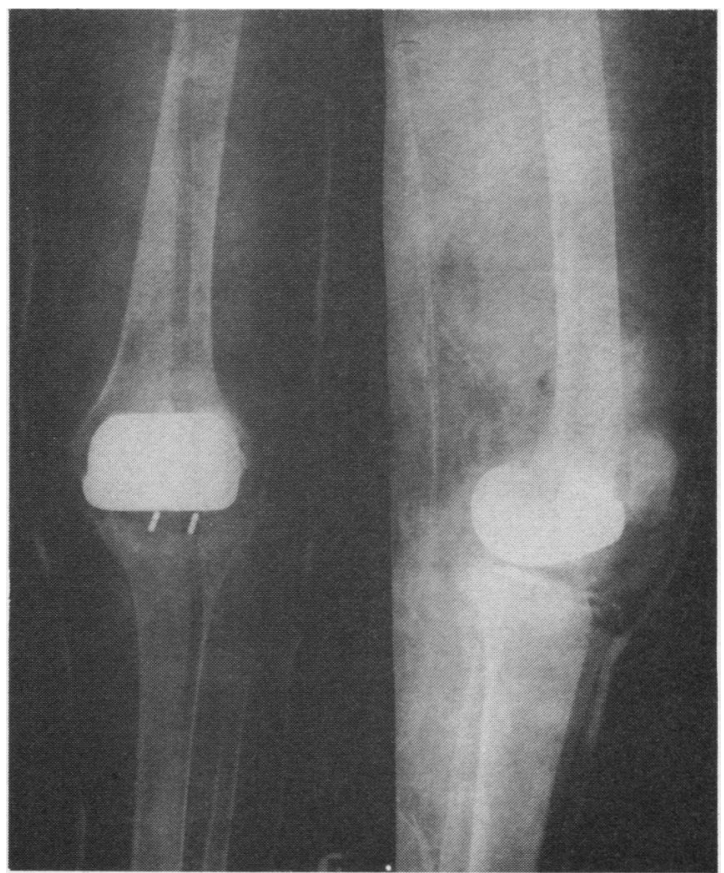

Fig. 3 This patient aged 72 with rheumatoid arthritis had a good result following a Freeman-Swanson arthroplasty. Nine years later she could flex her knee to $120^{\circ}$ and had no pain. 
Results. The complications in this series have been fewer and less severe than with the hinged prosthesis, but the good results have been few $(33 \%)$ (Table 11$)$.

Conclusions. This type of arthroplasty resulted in (1) moderate relief of pain; (2) fair stability; (3) unsuitable for severe deformities; (4) $16 \%$ deep infection; (5) $28 \%$ loosening of the prosthesis; (6) a salvage procedure was easier but only $50 \%$ were successfully fused.

Table 10 Complications (Freeman-Swanson)

\begin{tabular}{ll}
\hline Instability & 7 \\
Loosening & 5 \\
Deformity & 4 \\
Infection & 3 \\
Skin necrosis & 1 \\
\hline
\end{tabular}

Table 11 Freeman-Swanson knee arthroplasty

\begin{tabular}{ll}
$\begin{array}{l}\text { Follow-up 6-7 yr } \\
\text { Results }\end{array}$ & \multicolumn{1}{c}{18 Knees } \\
\hline $\left.\begin{array}{ll}\text { Excellent } & 2 \\
\text { Good } & 4\end{array}\right\} 33 \%$ \\
$\begin{array}{l}\text { Fair } \\
\text { Poor } \\
\text { Deaths }\end{array}$ & $\left.\begin{array}{l}5 \\
1\end{array}\right\} 67 \%$ \\
\hline
\end{tabular}

Table 12 Gunston knee arthroplasty

$\left.\begin{array}{ll}\hline \begin{array}{l}\text { Follow-up } 6 y r \\ \text { Results }\end{array} & 9 \text { Knees } \\ \hline \text { Excellent } & 0 \\ \text { Good } & 3 \\ \text { Fair } & 2 \\ \text { Poor } & 4\end{array}\right\} 67 \%$

GUNSTON KNEE PROSTHESIS ${ }^{3}$ (1973-4)

During the last 6 years we have carried out 9 Gunston arthroplasties on moderately damaged knees which had reasonable stability and a minimal deformity (Fig. 4).

Complications. Loosening of the plastic tibial gutters has occurred in one patient, and this arthroplasty was revised and replaced with an Attenborough prosthesis.

No instability and deformity has been seen, but a residual deformity was present in 3 cases.

Results. Only $33 \%$ have a good result, though serious complications have been few. But this type of arthroplasty is not applicable to the more severely damaged knee (Table 12).

Conclusions. This arthroplasty resulted in (1) moderate relief of pain; (2) no inherent stability; (3) a moderate correction of deformity; (4) a limited application; (5) no deep infection; (6) if removed for infection, fusion should be easy, as little bone is removed.

SHEEHAN KNEE ARTHROPLASTY ${ }^{4}$ (1976-8)

We have carried out only 8 of these arthroplasties during the last 3 years, and the follow-up is too short to assess the results (Fig. 5).

Complications. One patient developed loosening of the femoral prosthesis. This was revised and she had a successful result. An infection occurred in another case when the wound broke down. This eventually healed with treatment but resulted in a rather stiff knee.

\section{ATTENBOROUGH KNEE ARTHROPLASTY 5} (1975-8)

We have carried out 60 arthroplasties of this type
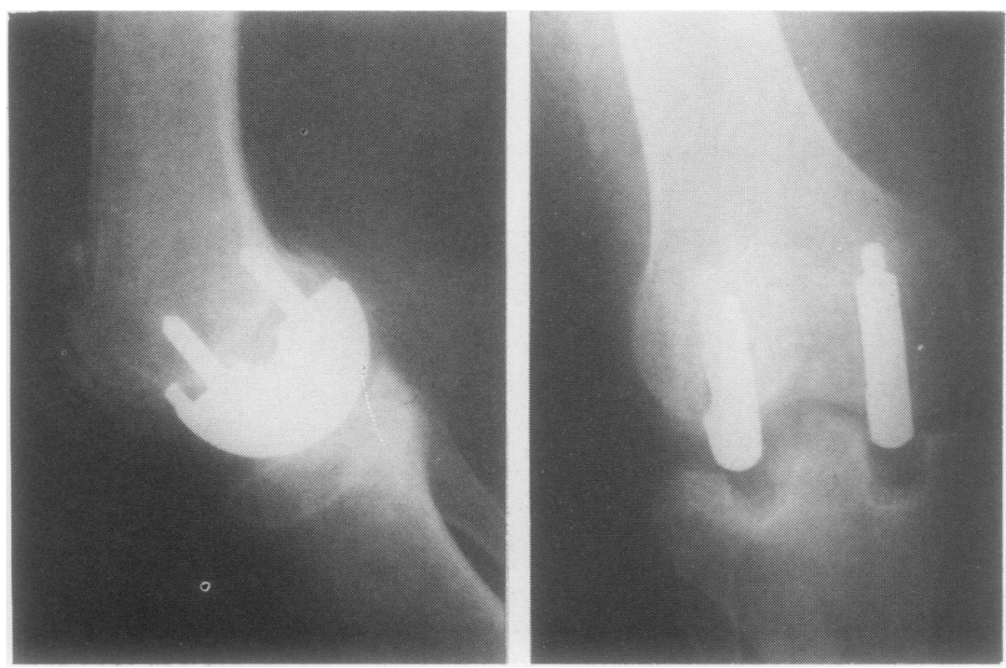

Fig. 4 This patient aged 63 with rheumatoid arthritis had a Gunston arthroplasty, and 4 years later she had no pain and $60^{\circ}$ of flexion. 
during the last 4 years, all patients suffering from rheumatoid diseases (Fig. 6).

Complications. The standard-sized prosthesis was too large for some of our stunted patients and difficulty was experienced in closing the capsule in 3 cases. A smaller sized prosthesis is now available to overcome this problem.

Two cases of infection have occurred.The prostheses were removed; one was successfully fused but the other developed a fibrous union. During the operation a fracture of the femoral condyle occurred in 2 cases, but they were well held by the cement and both progressed satisfactorily. In 3 cases the prosthesis became loose. These were revised by a modified Attenborough prosthesis with long stems (Table 13).

Results. Our experience has been limited to 60 cases, but the results, followed up in these cases for one to 4 years, are favourable. These results are the best that we have obtained with the 5 different prostheses used, the majority of patients having freedom from pain and a good range of movement with excellent stability (Table 14).
Table 13 Complications (Attenborough)

\begin{tabular}{ll}
\hline Skin necrosis & 3 \\
Loosening & 3 \\
Fracture & 2 \\
Infection & 2 \\
\hline
\end{tabular}

Table 14 Attenborough knee arthroplasty

Follow-up 1-4 yr 60 Knees

Results

$\left.\begin{array}{lr}\hline \text { Excellent } & 8 \\ \text { Good } & 34\end{array}\right\} 70 \%$

Conclusions. This arthroplasty gives (1) good relief of pain; (2) excellent stability; (3) good correction of any deformity; (4) a low infection rate $(3.3 \%) ;(5)$ a loosening rate of $5 \% ;(6)$ good salvage prospects by fusion as only $1-2 \mathrm{~cm}$ of bone is removed.

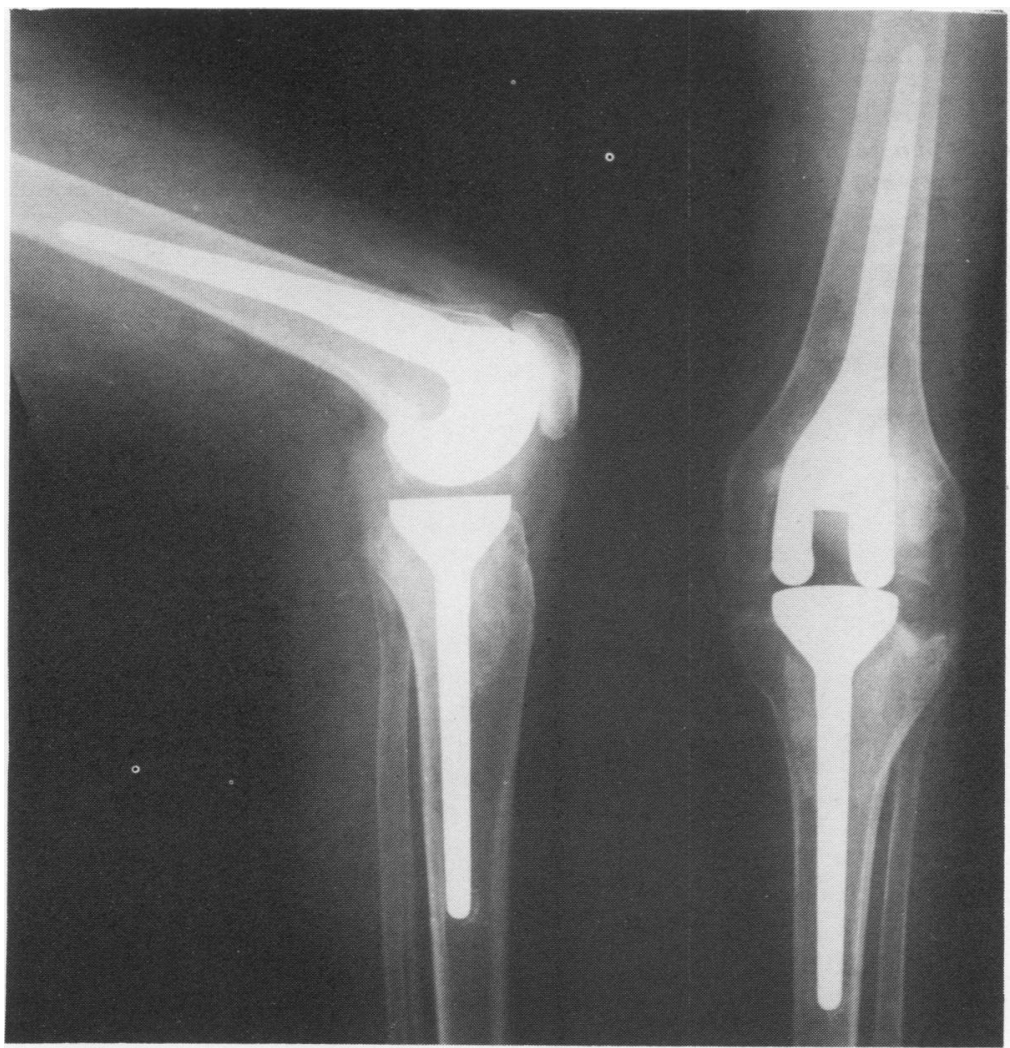

Fig. 5 This patient aged 47 with rheumatoid arthritis had a Sheehan knee arthroplasty. Four years later the range of movement was rather limited and the knee was somewhat painful. 


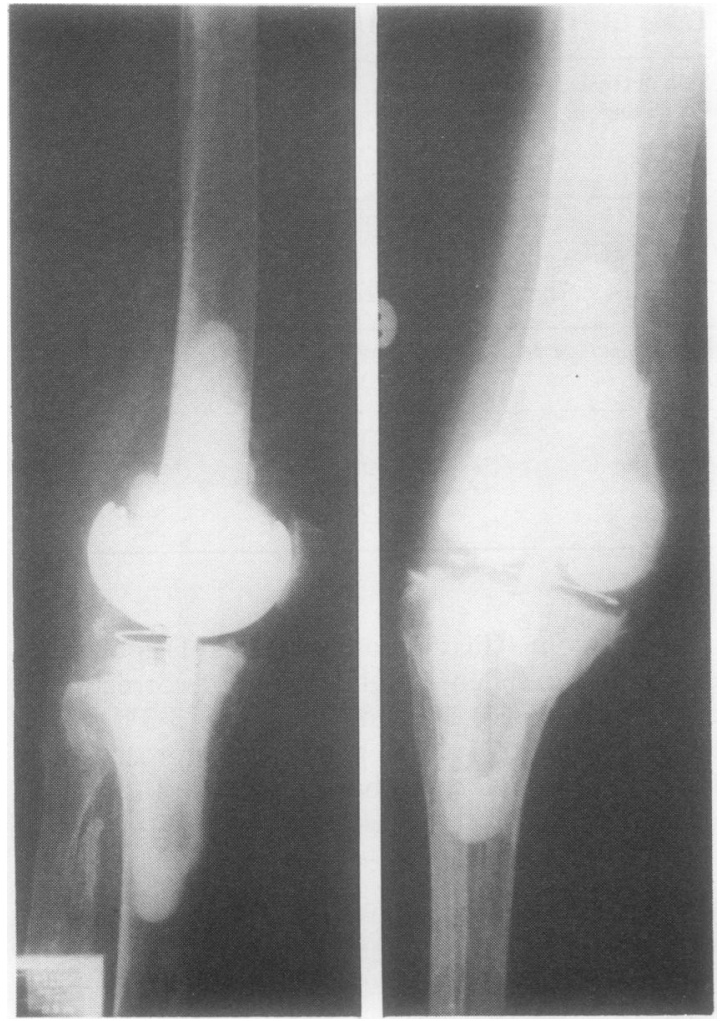

Fig. 6 This rheumatoid patient had an Attenborough total knee replacement of both knees and 3 years later had flexion in both knees to $90^{\circ}$ and no pain.

\section{Additional analysis}

A further analysis of data from the computer gave the following information: (1) The hinged knee prostheses have given the worst results and the linked knees the best. (2) Female and male patients have done equally well. (3) Patients with rheumatoid arthritis and juvenile chronic arthritis have done equally well. (4) Unilateral knee arthroplasties do better than bilateral cases. (5) The results continue to improve up to 5 years after operation but then slowly deteriorate.

Items 1-4 confirm our clinical conclusions and item 5 emphasises the necessity of a follow-up of more than 5 years.

This work was aided with grants from the Department of Health and Social Security and Arthritis and Rheumatism Council.

\section{References}

1 Shiers L G P. Arthroplasty of the knee; preliminary report of a new method. J Bone Joint Surg 1954; 36B: 553-60.

2 Freeman M A R, Swanson S A V. Total prosthetic replacement of the knee. J Bone Joint Surg 1972; 54B: 170-1.

3 Gunston F H. Polycentric knee arthroplasty; prosthetic simulation of normal knee movement. J Bone Joint Surg 1971; 53B: 272-7.

4 Sheehan J M. Arthroplasty of the knee. J Bone Joint Surg 1978; 60B: 333-8.

5 Attenborough C G. The Attenborough total knee replacement. J Bone Joint Surg 1978; 60B: 320-6. 